\title{
ST-segment depression in left precordial leads in electrocardiogram of patients with acute inferior myocardial infarction undergoing primary percutaneous coronary intervention
}

\author{
HOSSEIN NAMDAR, LEYLA IMANI, SAMAD GHAFFARI, NASER ASLANABADI, \\ NAJMEH RESHADATI, ZHILA SAMANI, GHITI DAVARMOIN, NASER MOAYYEDNIA, \\ YALDA NAZER, SHAHLA SARHANGZADEH, AHMAD SEPARHAM*
}

\begin{abstract}
Department of Cardiology, Cardiovascular Research Center, Madani Heart Center, Tabriz University of Medical Sciences, Tabriz, Iran ${ }^{*}$ Corresponding author: Ahmad Separham; Department of Cardiology, Cardiovascular Research Center, Madani Heart Center, Tabriz University of Medical Sciences, Daneshgah Ave, Tabriz 5166614756, Iran; Phone/Fax: +98 413336 3880; E-mail: aseparham@gmail.com
\end{abstract}

(Received: December 29, 2017; Revised manuscript received: March 16, 2018; Accepted: March 19, 2018)

\begin{abstract}
Background: The early identification of patients with acute inferior ST-segment elevation myocardial infarction (STEMI) with high risk features is particularly important. Acute inferior STEMI may be associated with ST-segment depression in the left precordial leads (V4-V6). This study assessed prognostic value of ST-segment depression in these left precordial leads during the admission of patients with acute inferior STEMI treated with primary percutaneous coronary intervention. Methods: This retrospective study enrolled 1,374 patients with acute inferior STEMI who underwent primary percutaneous coronary angioplasty between March 2011 and June 2014. The patients were divided into two groups: one group $(n=687)$ with left precordial ST-segment depression and the other $(n=687)$ without such ST-segment changes. Results: The patients with left precordial ST-segment depression were older and had higher incidence of hypertension, diabetes mellitus, and higher levels of troponin. In-hospital mortality was higher in patients with left precordial ST-segment depression. Advanced coronary artery disease was more observed in these patients. Conclusion: In patients with acute inferior STEMI treated with primary coronary intervention, left precordial ST-segment depression during admission of ECG is associated with more advanced coronary artery disease, and worse in-hospital clinical outcomes.
\end{abstract}

Keywords: acute inferior myocardial infarction, left precordial ST-segment depression, in-hospital mortality, SYNTAX score, primary coronary intervention

\section{Introduction}

The early identification of patients with acute inferior STsegment elevation myocardial infarction (STEMI) with high risk features is particularly important. Early risk stratification is particularly important in acute inferior STEMI due to its presumed better prognosis compared to acute anterior myocardial infarction (MI). Patients with acute inferior wall STEMI are usually considered at lower risk of in-hospital and long-term complication compared to anterior wall MI, although this type of infarction entails subsets of patients with a high likelihood of mortality and morbidity [1].
Because of widespread use and low costs, 12-lead electrocardiogram (ECG) is one of the most useful tools for predicting in-hospital and long-term outcomes in acute ST-segment MI. Several studies have reported the relationship between different patterns of electrocardiographic changes and mortality and morbidity associated with acute inferior wall MI $[2,3]$.

Acute inferior wall MI may be associated with STsegment depression in the left precordial leads. The etiology and clinical significance of this change in the ECG has been the subject of several studies in prethrombolytic and thrombolytic era [4-7].

This is an open-access article distributed under the terms of the Creative Commons Attribution-NonCommercial 4.0 International License, which permits unrestricted use, distribution, and reproduction in any medium for non-commercial purposes, provided the original author and source are credited, a link to the CC License is provided, and changes - if any - are indicated. 
In previous studies, mainly conducted in prethrombolysis and thrombolysis era, ST-segment depression in the left precordial leads has been associated with larger infarct size, more severe wall motion abnormality, lower left ventricular ejection fraction (LVEF) $[8,9]$, and unfavorable short- and long-term prognoses.

However, little is known about the prognostic significance of left precordial ST-segment depression in acute inferior wall MI in the modern era of reperfusion therapy including primary percutaneous coronary intervention (PCI) and aggressive medical therapy. Therefore, the purpose of this study was to examine the relationship between left precordial ST-segment depression and in-hospital outcomes in patients with acute inferior MI.

\section{Materials and Methods}

Between March 2011 and June 2014, a total of 1,374 patients with a diagnosis of acute inferior wall MI who were admitted within $12 \mathrm{~h}$ of symptom onset to our hospital and underwent primary percutaneous coronary angioplasty (PPCI) were enrolled. Acute inferior MI was defined as the following criteria: anginal chest pain lasting more than $30 \mathrm{~min}$, ST-segment elevation $\geq 1 \mathrm{~mm}$ in at least two of the inferior leads (II, III, and aVF), and elevation of cardiac enzymes including creatine kinase $\mathrm{MB}$ and/or troponin-I more than twice the upper limits of normal. All ST-segment measures were assessed and compared between baseline ECG in emergency room and 60 min after PPCI. ST-segment depression was defined as $S T$-depression $\geq 1 \mathrm{~mm} 80 \mathrm{~ms}$ after the J point using the PR segment as baseline. ST-segment recovery was measured by single-lead ST-segment resolution (STR). A decrease in ST-segment elevation $\geq 50 \%$ in the lead with maximal ST-segment elevation at baseline ECG was defined as complete STR. All patients were provided aspirin $(325 \mathrm{mg})$ and clopidogrel $(600 \mathrm{mg})$ during the admission in the emergency room. A bolus of $100 \mathrm{IU} / \mathrm{kg}$ of IV heparin was administrated. PPCI of culprit vessel was performed through femoral route. Coronary stenosis $\geq 70 \%$ were considered significant and multivessel disease was defined as the presence of lesions $\geq 70 \%$ of the diameter stenosis in $\geq 2$ major coronary arteries. Coronary artery disease severity was also measured by synergy between PCI with taxus and cardiac surgery score (SYNTAX score) [10]. The selection of the revascularization procedure including multivessel PCI was based on operator's decision and coronary anatomy. The procedural decisions, such as stent type (drug-eluting stent or bare metal stent), size, length selection, and usage of glycoprotein IIb/IIIa inhibitors or thrombectomy device, were made according to the discretion of the interventional cardiologist of the procedure.
Coronary intervention and stenting for non-culprit significant stenosis in patients with two or three vessel diseases was performed at other session at same hospitalization. Exclusion criteria included patients with the admission of uninterpretable ECG, left ventricular hypertrophy, intraventricular conduction delays, WolffParkinson-White syndrome, digoxin use, and paced rhythm. We also excluded patients with normal coronary angiogram or non-obstructive coronary artery disease or patients who were candidate for coronary artery bypass graft surgery due to coronary anatomy. The study was approved by local ethics committee and informed consent was obtained from all the patients.

Patients were divided into two groups based on the presence or absence of ST-segment depression in left precordial leads (V4-V6): (1) First group with left precordial ST-segment depression was defined, if maximal ST-segment depression (ST-segment depression $\geq 0.1 \mathrm{mV}$ in $\geq 1$ lead) was present in leads V4-V6 or sum of STsegment depression in leads V4-V6 was greater than the sum of ST-segment depression in leads V1-V3. (2) Second group without left precordial ST-segment depression was defined, if there was less than $0.1 \mathrm{mV}$ ST-segment depression in leads V4-V6 in or sum of ST-segment depression in leads V1-V3 was equal or greater than the sum of ST-segment depression in leads V4-V6. Division of patients into two groups was based only on first ECG during admission in emergency room and not later. Therefore, first ECG obtained at emergency department was used to evaluate ST-segment depression in V4-V6 leads and enrollment of patients to the group with left precordial ST-segment depression or other group. Baseline epidemiologic, clinical, and hemodynamic characteristics, such as age, gender, risk factors, duration of ischemia, admission Killip class, and ST-segment, were recorded and compared between two groups. In addition, we compared catheterization data and coronary artery disease involvement in patients with and without left precordial ST-segment depression. We defined major adverse clinical events (MACE) as inhospital death, pulmonary edema, repeat $\mathrm{MI}$, complete heart block (CHB), and ventricular arrhythmia. We compared these endpoints between two groups.

\section{Statistical analyses}

For continuous variables, data were expressed as means \pm SD and categorical data as prevalence and percentages. Differences between groups were assessed by Student's $t$ test for continuous variables and the $\chi^{2}$ test for categorical variables. All tests of significance were two-tailed, and $p$ values of $<0.05$ were considered significant. The statistical analyses were performed by SPSS version 17.0 for Windows (SPSS Inc., Chicago, IL, USA). 


\section{Results}

The study population included 1,374 patients, divided into two groups each consists of 687 patients. Patients with maximal left precordial ST-segment depression were older and had higher prevalence of diabetes mellitus and hypertension (Table I). This group also had more prolonged ischemic time than the patients without left precordial ST-segment depression. They also had higher peak creatine phosphokinase and cardiac troponin I levels. Moreover, deteriorated hemodynamic status during presentation as evident by higher Killip class and lower systolic blood pressure were mostly found in patients with left precordial ST-segment depression group compared to patients without such ECG changes. No differences were observed between the two groups in terms of hospital stay. Although there were more number of men than women in both groups, the difference between the genders was not statistically significant $(p=0.1)$. Lower LVEF was observed in patients with left precordial ST-segment depression. Regarding arrhythmic events, $\mathrm{CHB}$ and ventricular arrhythmia were not significantly different between two groups. Inhospital mortality of patients with left precordial ST-segment depression was almost three times higher than other group. In addition, other MACE rate including pulmonary edema and reinfarction was higher in patients with left precordial ST-segment depression (Table II).

STR $\geq 50 \%$ was observed in 475 (69.1\%) of the patients in the left precordial ST-segment depression group and $516(75.1 \%)$ of the patients without left precordial STsegment depression $(p=0.016)$, suggesting a less favorable response to mechanical reperfusion in patients with this type of ECG changes.

Table III shows angiographic findings. Multivessel coronary artery disease was more common in patients with left precordial ST-segment depression than the other group $(69.8 \%$ vs. $62.9 \% ; p=0.008)$. In addition, mean

Table I Baseline characteristics of patients

\begin{tabular}{|c|c|c|c|c|}
\hline & & $\begin{array}{c}\text { Patients with left precordial } \\
\text { ST-segment depression }(n=687)\end{array}$ & $\begin{array}{l}\text { Patients without left precordial } \\
\text { ST-segment depression }(n=687)\end{array}$ & $p$ value \\
\hline Age (years) & & $66.13 \pm 11.35$ & $63.14 \pm 1.50$ & $<0.001$ \\
\hline Male & & $454(64.1 \%)$ & $482(70.2 \%)$ & 0.10 \\
\hline Total ischemic time $(\mathrm{h})$ & & $8.14 \pm 2.3$ & $7.27 \pm 3.1$ & $<0.0001$ \\
\hline Smoking $[n(\%)]$ & & $198(28.82 \%)$ & $225(32.75 \%)$ & 0.11 \\
\hline $\operatorname{HTN}[n(\%)]$ & & $381(55.5 \%)$ & $339(49.3 \%)$ & 0.02 \\
\hline Diabetes mellitus $[n(\%)]$ & & $195(28.38 \%)$ & $147(21.39 \%)$ & 0.003 \\
\hline Hyperlipidemia [ $n(\%)]$ & & $108(15.72 \%)$ & $84(12.22 \%)$ & 0.06 \\
\hline Family history of CAD $[n(\%)]$ & & $36(5.24 \%)$ & $27(3.93 \%)$ & 0.24 \\
\hline Previous CAD $[n(\%)]$ & & $45(6.55 \%)$ & $36(5.24 \%)$ & 0.30 \\
\hline Previous CABG $[n(\%)]$ & & $12(1.74 \%)$ & $6(0.87 \%)$ & 0.15 \\
\hline Previous PCI $[n(\%)]$ & & $9(1.31 \%)$ & $18(2.62 \%)$ & 0.08 \\
\hline $\mathrm{SBP}(\mathrm{mmHg})$ & & $109.2 \pm 23.6$ & $112.7 \pm 25.1$ & 0.007 \\
\hline $\mathrm{DBP}(\mathrm{mmHg})$ & & $87.3 \pm 17.1$ & $86.96 \pm 18.7$ & 0.72 \\
\hline Heart rate (beats/min) & & $72.2 \pm 9.3$ & $70.4 \pm 7.5$ & 0.88 \\
\hline Peak CTnI (ng/ml) & & $28.6 \pm 56.50$ & $9.0 \pm 4.44$ & 0.002 \\
\hline Peak CPK $(\mathrm{U} / \mathrm{L})$ & & $1,854.126 \pm 79.70$ & $1,261.76 \pm 38.29$ & $<0.001$ \\
\hline Peak CK-MB (U/L) & & $289.11 \pm 56.70$ & $244.39 \pm 70.03$ & 0.44 \\
\hline $\operatorname{LEVF}(\%)$ & & $40.00 \pm 10.42$ & $43.60 \pm 10.49$ & $<0.001$ \\
\hline $\begin{array}{l}\text { Duration of hospital stay } \\
\text { (days) }\end{array}$ & & $5.0 \pm 58.18$ & $5.0 \pm 94.30$ & 0.30 \\
\hline $\begin{array}{l}\text { Killip class during admission } \\
{[n(\%)]}\end{array}$ & $\begin{array}{l}\text { I } \\
\text { II } \\
\text { III } \\
\text { IV }\end{array}$ & $\begin{array}{c}543(79 \%) \\
75(10.9 \%) \\
24(3.5 \%) \\
45(6.6 \%)\end{array}$ & $\begin{array}{c}555(80.8 \%) \\
90(13.1 \%) \\
15(2.2 \%) \\
27(3.9 \%)\end{array}$ & 0.04 \\
\hline
\end{tabular}

Data are presented as the mean \pm standard deviation or $n(\%)$. CAD: coronary artery disease; CABG: coronary artery bypass graft surgery; PCI: percutaneous coronary intervention; SBP: systolic blood pressure; DBP: diastolic blood pressure; CPK: creatine phosphokinase; CK- MB: creatine kinase- MB; CTnI: cardiac troponin I; LVEF: left ventricular ejection fraction; PCI: percutaneous coronary intervention 
Namdar et al.

Table II Adverse cardiac events

\begin{tabular}{lccc} 
& $\begin{array}{c}\text { Patients with left precordial } \\
\text { ST-segment depression } \\
(n=687)[n(\%)]\end{array}$ & $\begin{array}{c}\text { Patients without left } \\
\text { precordial ST-segment } \\
\text { depression }(n=687)[n(\%)]\end{array}$ & $p$ value \\
Mortality & $70(10.18 \%)$ & $22(3.20 \%)$ & $<0.001$ \\
Pulmonary edema & $64(9.31 \%)$ & $8(1.16 \%)$ & $<0.001$ \\
Re-MI & $21(3.05 \%)$ & $9(1.31 \%)$ & 0.02 \\
Ventricular arrhythmias & $81(11.8 \%)$ & $76(11.06 \%)$ & 0.73 \\
Complete heart block & $73(10.62 \%)$ & $66(9.60 \%)$ & 0.59 \\
\hline
\end{tabular}

Re-MI: repeat myocardial infarction

Table III Angiographic and procedural data

\begin{tabular}{lccc} 
& $\begin{array}{c}\text { Patients with left precordial } \\
\text { ST-segment depression }(n=687)\end{array}$ & $\begin{array}{c}\text { Patients without left precordial } \\
\text { ST-segment depression }(n=687)\end{array}$ & $p$ value \\
\hline Single-vessel disease $[n(\%)]$ & $208(30.2 \%)$ & $255(37.1 \%)$ & 0.008 \\
Multivessel disease $[n(\%)]$ & $479(69.8 \%)$ & $432(62.9 \%)$ & 0.008 \\
TIMI flow 0-1 before PCI $[n(\%)]$ & $421(61.2 \%)$ & $379(55.1 \%)$ & 0.024 \\
Use of glycoprotein IIb/IIIa inhibitor & $511(74.3 \%)$ & $499(72.6 \%)$ & 0.500 \\
{$[n(\%)]$} & & & $<0.0001$ \\
Total number of stents & $2.43 \pm 0.4$ & $24.2 \pm 8.6$ & 0.002 \\
Total stent length $(\mathrm{mm})$ & $25.3 \pm 4.1$ & $568(82.6 \%)$ & 0.610 \\
DES implantation & $576(83.8 \%)$ & $19.8 \pm 7.9$ & $<0.0001$ \\
SYNTAX score & $30.1 \pm 5.1$ & & 0.042 \\
Infarct-related artery & & $526(76.5 \%)$ & 0.016 \\
RCA $[n(\%)]$ & $492(71.6 \%)$ & $161(23.4 \%)$ & 0.028 \\
LCX $[n(\%)]$ & $195(28.38 \%)$ & $364(52.9 \%)$ & $23(3.3 \%)$ \\
Thrombus grade $4-5[n(\%)]$ & $409(59.5 \%)$ & $41(5.9 \%)$ &
\end{tabular}

DES: drug-eluting stent; RCA: right coronary artery; LCX: left circumflex coronary artery; TIMI: thrombolysis in myocardial infarction; SYNTAX: synergy between PCI with taxus and cardiac surgery; PCI: percutaneous coronary intervention

SYNTAX score was significantly higher in these patients $(30.1 \pm 5.1$ vs. $19.8 \pm 7.9 ; p<0.0001)$.

Left anterior descending (LAD) artery stenosis being more than $70 \%$ was observed in 236 patients with left precordial ST-segment depression and 180 patients without left precordial ST-segment depression $(p=0.001)$. Patients with left precordial ST-segment depression had higher incidence of left circumflex coronary artery (LCX) as culprit lesion than the other group $(28.38 \%$ vs. $23.4 \%$; $p=0.042)$.

\section{Discussion}

The main findings of this study can be summarized as follows. First, patients with left precordial ST-segment depression (leads V4-V6) during acute inferior MI had unfavorable epidemiologic and clinical characteristics including older age, more prevalent diabetes and hypertension, prolonged ischemic time, and worse hemodynamic status. Second, more impaired left ventricular systolic function, higher peak cardiac troponins, more advanced coronary artery involvement, and more severe mitral regurgitation were found in these patients. Third, these patients had less optimal response to reperfusion therapy as evident by lower complete STR following primary angioplasty. Finally, patients with left precordial STsegment depression during acute inferior STEMI had poor short-term prognosis.

Acute inferior wall $\mathrm{MI}$ is generally considered more benign compared to anterior wall MI, but certain subgroups are at increased risk of in-hospital and long-term mortality and complications. Patients with ST-segment depression in left precordial leads (V4-V6) during 
admission are one of these groups with unfavorable prognosis. In this study, ST-segment alterations in V4V6 leads were visible from the onset of acute MI.

The diagnostic and prognostic value of this type of electrocardiographic change in patients with acute inferior MI has been widely discussed in several studies mostly in prethrombolytic and thrombolytic area. There are paucity of data regarding prognostic implication of left precordial ST-segment depression in the modern era of early invasive reperfusion of patients with acute inferior wall MI [11, 12]. Similar to the previous studies [13-15], this study showed that patients with left precordial STsegment depression were older and more likely to be diabetic. Therefore, this may be one of the possible explanations of worse in-hospital outcome in these patients, as diabetes mellitus and advanced age are considered as the prognostic factors in STEMI. Less well-known in previous studies, patients with left precordial ST-segment depression in this study had longer ischemic time. In addition to one of the possible mechanisms for less response to reperfusion therapy, prolonged myocardial ischemia may lead to larger infarct size, more severe left ventricular systolic dysfunction, and less myocardial salvage. Therefore, it is not surprising that these patients had more hemodynamic deterioration during initial presentation (as evident by higher Killip class and lower systolic blood pressure) and more in-hospital mortality.

Regarding coronary artery involvement, the results of this study were in line with most of the previous studies $[16,17]$ and showed that patients with left precordial STsegment depression during acute inferior MI were more likely to have multivessel coronary artery disease and unfavorable coronary anatomy as evident by higher SYNTAX score. Coronary anatomy measure like SYNTAX score is one of the independent prognostic factors in patients with STEMI who undergo primary percutaneous intervention [18, 19]. Higher SYNTAX score usually indicates more complicated procedure as shown here by more stent use and longer stents (Table III), less response to mechanical reperfusion, and more development of noreflow phenomenon $[20,21]$. Therefore, incomplete STR and higher peak troponin in patients with left precordial ST-segment depression in this study may partly be due to this phenomenon. Other angiographic finding in this study, which may explain worse outcome in these patients with left precordial ST-segment depression, is lower baseline coronary thrombolysis in MI flow (Table III). Previous studies have shown unfavorable in-hospital and long-term prognosis of patients with STEMI who are presented with poor preprocedural coronary blood flow [22-24]. Another explanation for higher myocardial necrosis may be the larger thrombus burden (Table III) in these patients, which leads to higher incidence of distal embolization and microvascular dysfunction. Overall, patients with left precordial ST-segment depression in this study had delayed reperfusion.
Therefore, older organized intracoronary thrombus may be resistant to mechanical reperfusion resulting in noreflow phenomenon and poor myocardial perfusion. Similar to some previous studies $[5,25]$, we showed that LAD artery significant stenosis was more prevalent in this group of patients. LAD stenosis may translate to greater jeopardized myocardium, left ventricular anterior wall ischemia and necrosis, and more depressed systolic function. This may be another reason of high mortality and poor in-hospital outcome of patients with this type of STsegment depression in acute inferior MI. In addition, in this study, LCX as culprit vessel was more prevalent in patients with left precordial ST-segment depression. This may be another possible explanation of higher mortality and heart failure in these patients, as previous studies have shown increased in-hospital and long-term mortality of patients with LCX-related inferior MI $[26,27]$. In the setting of acute coronary syndrome other than acute inferior MI, ST-segment depression alone is usually not useful in predicting the site of coronary occlusion [28]. Rather, ST-segment depression in V4-V6 is highly suggestive of multivessel and/or left main stenosis in patients with non-ST-segment elevation acute coronary syndrome $[29,30]$. Nevertheless, there are some reports that could challenge this concept. Nikus et al. [31] showed than in patients with ST-segment depression in V4-V5 and positive $\mathrm{T}$ wave in same leads, LAD stenosis was culprit vessel in $74 \%$ of patients. Another study by Misumida et al. [32] showed in three of six patients with non-STEMI, upsloping ST-segment depression in V2-V6 was associated with significant LAD stenosis. Of course, small number of patient in these two studies precludes definite conclusion and further studies with adequate power are warranted.

Historically, left precordial ST-segment depression during acute inferior MI has been associated with high in-hospital mortality up to $41 \%$ in previous studies [33]. This study showed despite major improvement in reperfusion therapy and cardiac care in STEMI patients in recent years, this type of ST-segment changes still was associated with high mortality rate, almost three times higher than patients without left precordial ST-segment depression (10.1\% vs. $3.2 \%$ ). Of course, the total inhospital mortality rate in this study $(6.7 \%)$ is identical to a recent study by Kumar et al. [34], which compared short-term outcomes of patients with inferior MI based on presence or absence of conduction blocks (6.8\%). However, another study by Jim et al. [35] reported higher mortality rate $(12.6 \%)$ than our cohort probably due to fewer reperfusion therapy in their study.

The exact mechanism responsible for left precordial ST-segment depression during acute inferior STEMI remains unknown $[9,36,37]$. Remote anterior or lateral wall ischemia due to reduced coronary blood flow in non-culprit vessels may be one of the possible mechanisms [38]. Liga et al. recently showed that two thirds of patients with STEMI have severely reduced 
coronary perfusion at non-culprit vessels that predicted reciprocal. ST-segment depression occurs during acute phase [39].

Another possible etiology may be related to increased left ventricular diastolic pressure, as one small study [40] has shown that patients with left precordial ST-segment depression had higher levels of atrial natriuretic peptide, which means higher stretch of left atrium due to increased left ventricular filling pressure in the setting of diffuse myocardial ischemia. Advanced coronary artery disease in this study in patients with left precordial ST-segment depression may support this theory. This study had several major limitations: First of all, resolution of ST-segment depression was not addressed in this study as recent studies have shown independent prognostic effect of failed STsegment depression resolution on in-hospital and longterm mortality in patients treated with primary angioplasty $[41,42]$. Other major limitation was retrospective, single center, and non-randomized nature of this study with relatively small sample size. In addition, we did not separate patients with maximal ST-segment depression in leads $\mathrm{V} 1-\mathrm{V} 3$ as a distinct group, which may influence our results and conclusions. Therefore, further studies with larger sample size and long-term follow-up with considering ST-segment depression resolution is required to better define the prognostic implication of left precordial STsegment depression in the acute inferior ST-segment elevation MI. Meanwhile, this study showed that patients with this type of ST-segment changes during inferior MI are at increased risk of adverse in-hospital outcome and need aggressive treatment and hospital care.

\section{Conclusion}

This study showed that in patients with acute inferior STEMI undergoing PPCI, left precordial ST-segment depression during ECG admission defines a high risk category with unfavorable baseline characteristics, less response to mechanical reperfusion, more advanced coronary artery disease, and worse in-hospital clinical outcome.

$$
* * *
$$

Funding sources: None.

Authors' contribution: AS and HN performed research design and contributed to the writing of manuscript. LI, ZS, GD, YN, and SS performed data collection. SG, NA, and NR revised and approved the final version of the manuscript. NM performed data analysis and interpretation of data. All authors had full access to all data in the study and take responsibility for the integrity of the data and the accuracy of the data analysis. All the authors reviewed and approved the final version of the manuscript.

Conflict of interest: The authors declared no potential conflict of interest with respect to the research, authorship, and/or publication of this article.

\section{References}

1. Berger PB, Ryan YJ: Inferior myocardial infarction: High risk subgroups. Circulation 81, 401-411 (1990)

2. Bates ER, Clemmensen PM, Califf RM, Gorman LE, Aronson LG, George BS, Kereiakes DJ, Topol EJ: Precordial ST segment depression predicts a worse prognosis in inferior infarction despite reperfusion. J Am Coll Cardiol 16, 1538-1544 (1990)

3. Shah PK, Pichler M, Bermon DS, Maddahi J, Peter T, Singh BN, Swan HJ: Non-invasive identification of a high risk subset of patients with acute inferior myocardial infarction. Am J Cardiol 46, 915-921 (1980)

4. Birnbaum Y, Herz I, Sclarovsky S, Zlotikamien B, Chetrit A, Olmer L, Barbash GI: Prognostic significance of precordial ST segment depression on admission electrocardiogram in patients with inferior wall myocardial infarction. J Am Coll Cardiol 28, 313-318 (1996)

5. Strasberg B, Pinchas A, Barbash GI, Hod H, Rat S, Har-Zahav Y, Caspi A, Sclarovsky S, Agmon J: Importance of reciprocal ST segment depression in leads V5 and V6 as an indicator of disease of the left anterior descending coronary artery in acute inferior wall myocardial infarction. Br Heart J 63, 339-341 (1990)

6. Ong L, Valdellon B, Coromilas J, Brody R, Reiser P, Morrison J: Precordial S-T segment depression in inferior myocardial infarction: Evaluation by quantitative thallium-201 scintigraphy and technetium-99m ventriculography. Am J Cardiol 51, 734-739 (1983)

7. Gibson RS, Crampton RS, Watson DD, Taylor GJ, Carabello BA, Holt ND, Beller GA: Precordial ST-segment depression during acute inferior myocardial infarction: Clinical, scintigraphic and angiographic correlations. Circulation 66, 732-741 (1982)

8. Roubin GS, Shen WF, Nicholson M, Dunn RF, Kelly DT, Harris PJ: Anterolateral ST segment depression in acute inferior myocardial infarction angiographic and clinical implications. Am Heart J 107, 1177-1182 (1984)

9. Hasdai D, Jabara R, Sclarovsky S, Imbar S, Sagie A: Pathophysiology of precordial ST-segment depression in inferior wall acute myocardial infarction: An echocardiographic appraisal. Cardiology 88, 361-366 (1997)

10. Sianos G, Morel MA, Kappetein AP, Morice MC, Colombo A, Dawkins K, van den Brand M, Van Dyck N, Russell ME, Mohr FW, Serruys PW: The SYNTAX score: An angiographic tool grading the complexity of coronary artery disease. EuroIntervention 1 , 219-227 (2005)

11. El Atroush H, Effat H, Shehata M, Emara H: Reciprocal ST segment changes in acute inferior myocardial infarction: Clinical, hemodynamic and angiographic implications. Egypt Heart J 64, 97-103 (2012)

12. Chen TE, Lo PH, Li TC, Lin KH, Lin JJ, Hsieh LC, Chang CP, Chen YP, Chang KC, Wang HJ: Prognostic significance of reciprocal ST-segment depression in patients with acute STEMI undergoing immediate invasive intervention. Am J Emerg Med 30, 1865-1871 (2012)

13. Birnbaum Y, Wagner GS, Barbash GI, Gates K, Criger DA, Sclarovsky S, Siegel RJ, Granger CB, Reiner JS, Ross AM: Correlation of angiographic findings and right (Vl to V3) versus left (V4 to V6) precordial ST-segment depression in inferior wall acute myocardial infarction. Am J Cardiol 83, 143-148 (1999)

14. Birnbaum Y, Herz I, Sclarovsky S, Zlotikamien B, Chetrit A, Olmer L, Barbash GI: Prognostic significance of precordial ST segment depression on admission electrocardiogram in patients with inferior wall myocardial infarction. J Am Coll Cardiol 28, 313-318 (1996)

15. Peterson ED, Hathaway WR, Zabel KM, Pieper KS, Granger CB, Wagner GS, Topol EJ, Bates ER, Simoons ML, Califf RM: Prognostic significance of precordial ST segment depression during inferior myocardial infarction in the thrombolytic era: Results in 16,521 patients. J Am Coll Cardiol 28, 305-312 (1996) 
16. Mager A, Sclarovsky S, Herz I, Adler Y, Strasberg B, Birnbaum Y: Value of initial electrocardiogram in patients with inferior-wall acute myocardial infarction for prediction of multi vessel coronary artery disease. Coron Artery Dis 11, 415-420 (2000)

17. Takayanagi K, Yamaguchi H, Morooka S, Takabatake Y: Higher Gensini score of coronary arteries in acute inferior myocardial infarction with precordial ST-segment depression. Jpn Heart J 33, 25-39 (1992)

18. Magro M, Nauta S, Simsek C, Onuma Y, Garg S, van der Heide E, van der Giessen WJ, Boersma E, van Domburg RT, van Geuns RJ, Serruys PW: Value of the SYNTAX score in patients treated by primary percutaneous coronary intervention for acute ST-elevation myocardial infarction: The MI SYNTAX score study. Am Heart J 161, 771-781 (2011)

19. Brkovic V, Dobric M, Beleslin B, Giga V, Vukcevic V, Stojkovic S, Stankovic G, Nedeljkovic MA, Orlic D, Tomasevic M, Stepanovic J, Ostojic M: Additive prognostic value of the SYNTAX score over GRACE, TIMI, ZWOLLE, CADILLAC and PAMI risk scores in patients with acute ST-segment elevation myocardial infarction treated by primary percutaneous coronary intervention. Int J Cardiovasc Imaging 29, 1215-1228 (2013)

20. Magro M, Nauta ST, Simsek C, Boersma E, van der Heide E, Regar E, van Domburg RT, Zijlstra F, Serruys PW, van Geuns RJ: Usefulness of the SYNTAX score to predict "no reflow" in patients treated with primary percutaneous coronary intervention for ST-segment elevation myocardial infarction. Am J Cardiol 109, 601-606 (2012)

21. van Gaal WJ, Ponnuthurai FA, Selvanayagam J, Testa L, Porto I, Neubauer S, Banning AP: The Syntax score predicts peri-procedural myocardial necrosis during percutaneous coronary intervention. Int J Cardiol 135, 60-65 (2009)

22. Stone GW, Cox D, Garcia E, Brodie BR, Morice MC, Griffin J, Mattos L, Lansky AJ, O’Neill WW, Grines CL: Normal flow (TIMI-3) before mechanical reperfusion therapy is an independent determinant of survival in acute myocardial infarction: Analysis from the primary angioplasty in myocardial infarction trials. Circulation 104, 636-641 (2001)

23. De Luca G, Ernst N, Zijlstra F, van 't Hof AW, Hoorntje JC, Dambrink JH, Gosslink AT, de Boer MJ, Suryapranata H: Preprocedural TIMI flow and mortality in patients with acute myocardial infarction treated by primary angioplasty. J Am Coll Cardiol 43, 1363-1367 (2004)

24. Rakowski T, Dudek D, Dziewierz A, Yu J, Witzenbichler B, Guagliumi G, Kornowski R, Hartmann F, Lansky AJ, Brener SJ, Mehran R, Stone GW: Impact of infarct-related artery patency before primary PCI on outcome in patients with ST-segment elevation myocardial infarction: The HORIZONS-AMI trial. EuroIntervention 8, 1307-1314 (2013)

25. Hasdai D, Birnbaum Y, Porter A, Sclarovsky S: Maximal precordial ST-segment depression in leads V4-V6 in patients with inferior wall acute myocardial infarction indicates coronary artery disease involving the left anterior descending coronary artery system. Int J Cardiol 58, 273-278 (1997)

26. Sohrabi B, Separham A, Madadi R, Toufan M, Mohammadi N, Aslanabadi N, Kazemi B: Difference between outcome of left circumflex artery and right coronary artery related acute inferior wall myocardial infarction in patients undergoing adjunctive angioplasty after fibrinolysis. J Cardiovasc Thorac Res 6, 101-104 (2014)

27. Chen YL, Hang CL, Fang HY, Tsai TH, Sun CK, Chen CJ, Chen SM, Yang CH, Hsieh YK, Wu CJ, Fu M, Yip HK: Comparison of prognostic outcome between left circumflex artery-related and right coronary artery-related acute inferior wall myocardial infarction undergoing primary percutaneous coronary intervention. Clin Cardiol 34, 249-253 (2011)
28. Li D, Li CY, Yong AC, Kilpatrick D: Source of electrocardiographic ST changes in subendocardial ischemia. Circ Res 82, 957-970 (1998)

29. Barrabés JA, Figueras J, Moure C, Cortadellas J, Soler-Soler J: Prognostic significance of ST segment depression in lateral leads I, aVL, V5 and V6 on the admission electrocardiogram in patients with a first acute myocardial infarction without ST segment elevation. J Am Coll Cardiol 35, 1813-1819 (2000)

30. Kosuge M, Kimura K: Clinical implications of electrocardiograms for patients with non-ST-segment elevation acute coronary syndromes in the interventional era. Circ J 73, 798-805 (2009)

31. Nikus KC, Eskola MJ, Virtanen VK, Vikman S, Niemelä KO, Huhtala H, Sclarovsky S: ST-depression with negative T waves in leads V4-V5 - A marker of severe coronary artery disease in non-ST elevation acute coronary syndrome: A prospective study of Angina at rest, with troponin, clinical, electrocardiographic, and angiographic correlation. Ann Noninvasive Electrocardiol 9, 207-214 (2004)

32. Misumida N, Kobayashi A, Schweitzer P, Kanei Y: Prevalence and clinical significance of up-sloping ST-segment depression in patients with non-ST-segment elevation myocardial infarction. Cardiol Res 6, 306-310 (2015)

33. Hasdai D, Sclarovsky S, Solodky A, Sulkes J, Strasberg B, Birnbaum Y: Prognostic significance of maximal precordial ST-segment depression in right (V1 to V3) versus left (V4 to V6) leads in patients with inferior wall acute myocardial infarction. Am J Cardiol 74, 1081-1084 (1994)

34. Kumar V, Sinha S, Kumar P, Razi M, Verma CM, Thakur R, Pandey U, Bhardwaj RS, Ahmad M, Bansal RK, Gupta S: Shortterm outcome of acute inferior wall myocardial infarction with emphasis on conduction blocks: A prospective observational study in Indian population. Anatol J Cardiol 17, 229-234 (2017)

35. Jim MH, Chan AO, Tse HF, Lau CP: Predictors of inhospital outcome after acute inferior wall myocardial infarction. Singapore Med J 50, 956-961 (2009)

36. Mirvis DM: Physiologic bases for anterior ST segment depression in patients with acute inferior wall myocardial infarction. Am Heart J 116, 1308-1322 (1988)

37. Billadello JJ, Smith JL, Ludbrook PA, Tiefenbrunn AJ, Jaffe AS, Sobe BE, Geltman EM: Implications of reciprocal ST segment depression associated with acute myocardial infarction identified by positron tomography. J Am Coll Cardiol 2, 616-624 (1983)

38. Schuster EH, Bulkley BH: Ischemia at a distance after acute myocardial infarction: A cause of early postinfarction angina. Circulation 62, 509-515 (1980)

39. Liga R, Orsini E, Caravelli P, De Carlo M, Petronio AS, Marzilli M: Interactions between reciprocal ST-segment downsloping during ST-elevated myocardial infarction and global cardiac perfusion and functional abnormalities. Am J Cardiol 119, 1902-1908 (2017)

40. Assali A, Gilad I, Herz I, Solodky A, Sulkes J, Strasberg B, Sclarovsky S: Atrial natriuretic peptide levels after different types of inferior wall myocardial infarction. Clin Cardiol 20, 717-722 (1997)

41. Tjandrawidjaja MC, Fu Y, Westerhout CM, White HD, Todaro TG, Van de Werf F, Mahaffey KW, Wagner GS, Granger CB, Armstrong PW: Resolution of ST-segment depression: A new prognostic marker in ST-segment elevation myocardial infarction. Eur Heart J 31, 573-581 (2010)

42. Reinstadler SJ, Baum A, Rommel KP, Eitel C, Desch S, Mende M, Metzler B, Poess J, Thiele H, Eitel I: ST-segment depression resolution predicts infarct size and reperfusion injury in STelevation myocardial infarction. Heart 101, 1819-1825 (2015) 